

https://doi.org/10.31533/pubvet.v15n02a742.1-7

\title{
Análise de diferentes substratos e métodos de superação da dormência de Tectona grandis L.f.
}

 \\ Gomes de Almeida Sousa ${ }^{2} \mathbb{9}$, Ana Clara Carneiro Fonseca ${ }^{10}$, Valéria Cardoso Lopes ${ }^{1} \mathbb{9}$, Bárbara \\ Gomes Ferreira ${ }^{40}$, Priscila Bezerra de Souza ${ }^{5 * 90}$
}

${ }^{1}$ Discente do curso de Engenharia Florestal, Universidade Federal do Tocantins. Gurupi-TO Brasil.

${ }^{2}$ Discente do Programa de Pós-Graduação em Ciências Florestais e Ambientais, Universidade Federal do Tocantins. Gurupi, -TO Brasil.

${ }^{3}$ Engenheiro Florestal, Mestre em Ciências Florestais e Ambientais, Universidade Federal do Tocantins. Gurupi -TO Brasil.

${ }^{4}$ Engenheira Civil, Mestre em Ciências Florestais e Ambientais, Universidade Federal do Tocantins. Gurupi -TO Brasil.

${ }^{5}$ Professora, Doutora em Engenharia Florestal, Universidade Federal do Tocantins. Gurupi -TO Brasil.

*Autor para correspondência, E-mail: priscilauft@uft.edu.br

Resumo. Objetivou-se avaliar os métodos de superação da dormência nas sementes de Tectona grandis L.f., (Teca), para se verificar a viabilidade dos mesmos na uniformização da germinação. Foram testados cinco métodos de superação da dormência para cada substrato, sendo: Testemunha (T1, T6); Sementes acondicionados sobre uma lona preta por 96 horas e submetidos a uma temperatura média de $25^{\circ} \mathrm{C}$ (T2, T7); Imersão das sementes em água corrente por 48 horas (T3, T8); Imersão das sementes por 72 horas (T4, T9); Imersão das sementes em água durante a noite e durante o dia, colocando-as ao sol, sobre uma lona plástica, repetindo a técnica por três dias e posteriormente colocar as sementes em água por mais 24 horas (T5, T10). Os tratamentos T1 a T5 foram utilizados no substrato areia lavada, e os tratamentos de T6 a T10, foram utilizados no substrato areia + terra orgânica. Os principais parâmetros avaliados foram: percentagem de germinação e índice de velocidade de germinação (IVG). Os dados foram submetidos à análise de variância, sendo as médias comparadas pelo teste de Tukey com nível de 5\% de significância. Os maiores valores de percentual de germinação e IVG foram obtidos nos tratamentos (T6) e (T7).

Palavras-chave: Germinação, parâmetros, sementes, substrato

\section{Analysis of different substrates and methods for overcoming dormancy of Tectona grandis L.f.}

Abstract. The objective was to evaluate the methods of overcoming dormancy in seeds of Tectona grandis L.f., (Teca), to verify their viability in uniform the seed germination. Five methods for overcoming dormancy were tested for each substrate, being them; Control (T1, T6); Seeds packed on a black canvas for 96 hours and submitted to an average temperature of $25^{\circ} \mathrm{C}$ (T2, T7); Immersion of the seeds in running water for 48 hours (T3, T8); Immersion of the seeds in water for 72 hours (T4, T9); Immersion of the seeds in water during the night and the day, placing them in the sun, on a plastic canvas, repeating the technique for three days and then placing the seeds in water for another 24 hours (T5, T10). Where the T1 to T5 treatments were used on the washed sand substrate, and the T6 to T10 treatments were used on the sand + organic soil substrate. The main parameters evaluated were: percentage of germination and germination speed index (IVG). The data were submitted to analysis of variance, and the means were compared using the Tukey test with a 5\% significance level. The highest values of percentage of germination and IVG were obtained in treatments (T6) and (T7).

Keywords: Germination, parameters, seeds, substrate 


\section{Análisis de diferentes sustratos y métodos para superar la latencia de Tectona grandis $\boldsymbol{L} . \boldsymbol{f}$.}

Resumen. El objetivo fue evaluar los métodos para superar la latencia en las semillas de Tectona grandis L.f., (Teca), para verificar su viabilidad en la germinación uniforme. Se probaron cinco métodos para superar la latencia para cada sustrato, siendo: Testigo (T1, T6); Semillas empacadas en una lona negra durante 96 horas y sometidas a una temperatura promedio de $25^{\circ} \mathrm{C}(\mathrm{T} 2, \mathrm{~T} 7)$; Inmersión de las semillas en agua corriente durante 48 horas (T3, T8); Inmersión de las semillas durante 72 horas (T4, T9); Inmersión de las semillas en agua durante la noche y durante el día, colocándolas al sol, sobre un plástico, repitiendo la técnica por tres días y luego colocando las semillas en agua durante otras 24 horas (T5, T10). Donde los tratamientos de T1 a T5 se usaron en el sustrato de arena lavada, y los tratamientos de T6 a T10, se usaron en el sustrato de arena + tierra orgánica. Los principales parámetros evaluados fueron: porcentaje de germinación e índice de velocidad de germinación (IVG). Los datos se sometieron a análisis de varianza, y las medias se compararon mediante la prueba de Tukey con un nivel de significancia de 5\%. Los valores más altos de porcentaje de germinación e IVG se obtuvieron en los tratamientos (T6) y (T7).

Palabras clave: Germinación, parámetros, semillas, sustrato

\section{Introdução}

A Tectona grandis L.f., conhecida popularmente como teca, é uma espécie arbórea de grande porte, rápido crescimento, e de origem asiática utilizada na produção de madeira para as mais diversas finalidades. É uma planta de tronco retilíneo, fácil de cultivar, pouco sujeita a pragas, doenças e muito resistente ao fogo. Menezes (2017) diz que a teca é muito valorizada no mercado mundial, podendo alcançar preços até três vezes maiores aos do mogno (Swietenia macrophylla King), sendo utilizada para todo tipo de construções bem como barcos, móveis luxuosos e molduras.

Os primeiros plantios comerciais no Brasil surgiram na década de 1960, no Estado do Mato Grosso, apesar de que, atualmente já ocorram em várias regiões brasileiras. Devido à sua importância, a espécie tem sido destinada à produção de madeira para reflorestamento comercial, evitando a exploração inapropriada de espécies nativas (Raposo et al., 2010).

Na Ásia, o ciclo de rotação da teca é variável de 60 a 100 anos. Segundo Favare (2013) no Brasil os plantios comerciais iniciaram-se pela empresa Cáceres Florestal S.A., localizada em Cáceres/MT devido aos fatores condicionantes como clima, fertilidade e os tratos silviculturais mais adequados que contribuíram para reduzir o ciclo de produção. Quando destinadas a obtenção de madeira para serraria, as plantações de teca apresentam rotação de plantios que variam de 20 a 25 anos de idade, contudo, durante seu ciclo a madeira retirada nos desbastes, são principalmente destinadas à construção civil.

O diásporo da teca é do tipo drupa, tetralocular, sendo esperado que contenha quatro sementes, sendo uma por lóculo. As sementes são pequenas, delicadas e oleaginosas, medindo de cinco a seis milímetros de comprimento. São protegidas por endocarpo e mesocarpo impermeável, tornando a germinação lenta e irregular, o que ocasiona dificuldades na produção de mudas, sendo necessário seu rompimento para a germinação das sementes. A estrutura responsável pela impermeabilidade do endocarpo e mesocarpo à água é uma camada de células paliçádicas, cujas paredes celulares são espessas e recobertas externamente por cutícula cerosa, contribuindo com a dormência. Seu potencial germinativo é pouco explorado, pois o percentual de germinação foi sempre menor do que os resultados dos testes de corte e de tetrazólio (Dias et al., 2009; Pasa \& Nascimento, 2012).

Para Bezerra et al. (2018) a produção de sementes de teca durante os últimos anos tem sido uma das maiores dificuldades para implantação de plantios florestais, pois são inseridas em um fruto, com o endocarpo e mesocarpo duros, tornando a germinação lenta e irregular, ocasionando dificuldades na produção de mudas. Dessa forma, se torna importante avaliar métodos de superação de dormência que melhor proporcionam uma boa germinação e desenvolvimento de mudas. 
Objetivou-se avaliar métodos de superação da dormência nas sementes de teca, a fim de verificar a viabilidade das mesmas na uniformização da germinação das mudas Tectona grandis L.f.

\section{Material e métodos}

O experimento foi conduzido no Laboratório de Sementes e no Viveiro Florestal de mudas da Universidade Federal do Tocantins - Campus Universitário de Gurupi -TO, a $280 \mathrm{~m}$ de altitude, sob as coordenadas $11^{\circ} 43^{\prime} 45^{\prime \prime}$ 'de latitude Sul e $49^{\circ} 04^{\prime} 07^{\prime \prime}$ de longitude Oeste. A colheita das sementes deuse após o completo amadurecimento dos frutos caídos ao solo, as mesmas foram coletadas entre o mês de junho e julho de 2017 e acondicionados em sacos de papel, em seguida foram transportadas até o Laboratório de Sementes-UFT, onde foram beneficiadas e selecionadas manualmente, descartando-se as que apresentavam injúrias ou deformações para a superação da dormência.

Foram testados cinco métodos de superação da dormência das sementes de Tectona grandis L.f., para cada substrato utilizado (Tabela 1).

Tabela 1. Descrição dos substratos e tratamentos utilizados para a superação da dormência em sementes de Tectona grandis L.f.

\begin{tabular}{|c|c|c|}
\hline Tratamentos & Substratos & Descrição dos Tratamentos \\
\hline $\mathrm{T} 1$ & Areia Lavada & Testemunha - Sementes que não receberam qualquer tratamento. \\
\hline $\mathrm{T} 2$ & Areia Lavada & $\begin{array}{l}\text { Sementes acondicionados sobre uma lona preta por } 96 \text { horas e submetidos a } \\
\text { uma temperatura média de } 25^{\circ} \mathrm{C} \text {. }\end{array}$ \\
\hline T3 & Areia Lavada & Imersão das sementes em água corrente por 48 horas (IPEF, 2003). \\
\hline $\mathrm{T} 4$ & Areia Lavada & Imersão das sementes em água corrente por 72 horas (Dias et al., 2009). \\
\hline T5 & Areia Lavada & $\begin{array}{l}\text { Imersão das sementes em saco de fibra, juntamente com um peso, para que o } \\
\text { mesmo ficasse mergulhado em água corrente. Posteriormente, colocou as } \\
\text { sementes sobre uma lona plástica durante o dia (sol) e durante a noite (água). } \\
\text { Repetiu-se essa técnica por três vezes e finalmente colocou as sementes em } \\
\text { água por mais } 24 \text { horas (Figueiredo et al., 2005). }\end{array}$ \\
\hline T6 & Areia Lavada + Terra preta & Testemunha - Sementes que não receberam qualquer tratamento. \\
\hline $\mathrm{T} 7$ & Areia Lavada + Terra preta & $\begin{array}{l}\text { Sementes acondicionados sobre uma lona preta por } 96 \text { horas e submetidos a } \\
\text { uma temperatura média de } 25^{\circ} \mathrm{C} \text {. }\end{array}$ \\
\hline $\mathrm{T} 8$ & Areia Lavada + Terra preta & Imersão das sementes em água corrente por 48 horas (IPEF, 2003). \\
\hline T9 & Areia Lavada + Terra preta & Imersão das sementes em água corrente por 72 horas (Dias et al., 2009). \\
\hline T10 & Areia Lavada + Terra preta & $\begin{array}{l}\text { Imersão das sementes em saco de fibra, juntamente com um peso, para que o } \\
\text { mesmo ficasse mergulhado em água corrente. Posteriormente, colocou as } \\
\text { sementes sobre uma lona plástica durante o dia (sol) e durante a noite (água). } \\
\text { Repetiu-se essa técnica por três vezes e finalmente colocar as sementes em } \\
\text { água por mais } 24 \text { horas (Figueiredo et al., 2005). }\end{array}$ \\
\hline
\end{tabular}

Após o tratamento da superação de dormência, as sementes foram semeadas diretamente em dois substratos: um substrato composto de área lavada, canteiro contendo uma camada de $20 \mathrm{~cm}$ de espessura de areia, distribuindo as sementes em sua superfície e cobrindo com uma camada de $1,0 \mathrm{~cm}$ de areia fina peneirada, exposta a pleno sol, o segundo substrato sendo composto de areia com terra orgânica (IPEF, 2003), ambos os substratos possuem um espaçamento das sementes de $10 \mathrm{~cm}$ x $5 \mathrm{~cm}$ (Figueiredo et al., 2005), e a temperatura ótima foi alcançada cobrindo-se a sementeira com lona plástica preta por 96 horas (IPEF, 2003).

Tomou-se cuidado com a realização da semeadura das sementes da seguinte forma: sementes que apresentavam a cicatriz de inserção do cacho (panícula), foram posicionadas para baixo, facilitando o desenvolvimento adequado do sistema radicular da plântula (Figueiredo et al., 2005).

$\mathrm{Na}$ semeadura, foram utilizadas 100 sementes por tratamento, sendo estes subdivididos em duas repetições de 50 sementes cada (Ferreira et al., 2016). O tempo de avaliação da análise das sementes de teca foi de acordo com Brasil (2009), que é de 28 dias, mais devido as sementes terem continuado a germinar, foram avaliados por 60 dias.

O delineamento experimental utilizado foi o inteiramente casualizado, com 10 tratamentos, 2 repetições e 50 sementes por repetição. 
As variáveis analisadas foram: porcentagem de germinação $(\% \mathrm{G})$; índice de velocidade de germinação (IVG) segundo Maguire (1962), tempo médio de germinação ( $\overline{\mathrm{t}}$ ) segundo Labouriau (1983) e velocidade média de germinação $(\overline{\mathrm{v}})$, utilizou-se a expressão:

$$
\overline{\mathrm{v}}=\frac{1}{\overline{\mathrm{t}}}
$$

Em que:

$\overline{\mathrm{v}}=$ velocidade média de germinação; $\overline{\mathrm{t}}=$ tempo médio de germinação.

Durante a condução do experimento o IVG foi avaliado diariamente até atingir os 60 dias após a semeadura das sementes, a germinação da primeira semente ocorreu no décimo primeiro dia após a semeadura, a equação utilizada foi proposta por Maguire (1962):

$$
I V G=\frac{N 1}{D Q}+\frac{N 2}{D 2}+\cdots+\frac{N n}{D n}
$$

Onde:

IVG = índice de velocidade de germinação; $\mathrm{N}$ = Número de plântulas verificadas no dia da contagem; $\mathrm{D}=$ números de dias após a semeadura em que foi realizada a contagem.

Os resultados foram submetidos à análise de variância, sendo as médias comparadas pelo teste de Tukey, a 5\% de probabilidade, através do software Assistat 7.7 (Francisco \& Carlos, 2016).

\section{Resultados e discussão}

O início da germinação das sementes ocorreu a partir do décimo primeiro dia com o tratamento T2 (sementes submetidas a uma temperatura média de $25^{\circ} \mathrm{C}$ e colocadas sobre uma lona preta por 96 horas), comprovando a melhor eficácia no rompimento do tegumento. Cabe ressaltar que os valores de (VMG) encontrados para T2 foi superior ao encontrado por Dias et al. (2009) que obteve o início da germinação na quarta semana utilizando o tratamento de imersão das sementes em ácido sulfúrico $(33,5 \%)$ por três minutos. Dessa forma, infere-se que a superação de dormência utilizando ácido sulfúrico mostra-se perigosa ao usuário podendo causar queimaduras e riscos durante o descarte da solução, pois se descartado de forma incorreta ocasiona sérios problemas ambientais.

O tratamento Testemunha com areia e terra orgânica (T6) e o tratamento onde as sementes foram acondicionadas sobre uma lona preta por 96 horas e submetidos a uma temperatura média de $25{ }^{\circ} \mathrm{C}$ com o substrato de areia e terra orgânica (T7) foram os tratamentos que apresentaram o maior índice de velocidade de germinação (IVG) 1,40 e 1,07, respectivamente. Neste sentido, vale lembrar que estes tratamentos foram os que obtiveram melhores resultados em relação a porcentagem de germinação, provavelmente devido ao uso do substrato terra orgânica e à alta eficiência no rompimento do tegumento ocasionado por altas temperaturas (Tabela 2).

O tratamento (T6) Testemunha composto por areia e terra orgânica apresentou um percentual de germinação significativamente superior às sementes que foram utilizados tratamentos pré-germinativos, apresentando um porcentual de $65 \%$. Esse desempenho germinativo relativamente superior em areia e terra orgânica, em comparação aos demais substratos, pode ser atribuído à adaptação e ocorrência da espécie em locais com solos arenosos e a necessidade da superação de dormência da semente (Martins et al., 2008). O tratamento (T1) substrato somente com areia e sementes que não receberam qualquer tratamento obteve um valor de germinação de 13\%, corroborando com Resende et al. (2011), onde afirmam que o substrato composto apenas por areia não possibilita uniformidade na capacidade de retenção de água, devido à evaporação e ao rápido escoamento e isso pode acarretar maior dificuldade no processo de embebição contínua da semente e germinação.

$\mathrm{O}$ tratamento (T7) que submeteu as sementes a uma temperatura média de $25^{\circ} \mathrm{C}$ colocando-as sobre uma lona preta por 96 horas com substrato areia com terra orgânica apresentou um percentual de germinação de $45 \%$, sendo superior significativamente entre os tratamentos pré-germinativos (Tabela 
2). Dessa forma, pode-se inferir que esse tratamento pode ser uma alternativa viável e sustentável para a superação de dormência de Tectona grandis pois tratamentos de superação de dormência que utilizam ácido sulfúrico demostram ser eficientes, entretanto podem ser custosos e perigosos aos usuários.

Observou-se que as sementes tratadas em água corrente por 72 horas (T4 e T9) apresentaram uma taxa de germinação de $24 \%$ e $26 \%$ respectivamente, valor muito abaixo do encontrado por Lamprecht (1990) e Dias et al. (2009), onde os valores encontrado por este autores foram superiores a $70 \%$ de germinação, sendo um dos tratamentos mais empregado para o rompimento do endocarpo e mesocarpo nas sementes de teca. O tratamento (T3) com Imersão das sementes em água corrente por 48 horas foi o método que teve a menor taxa de germinação, quando comparada aos testes que sofreram algum tratamento pré-germinativo, segundo Dias et al. (2009) isto pode ser devido ao fato de ter comprometido o embrião das sementes, ou não ter rompido a camada impermeável à entrada de água no diásporo.

Os resultados obtidos pelos tratamentos que utilizaram como substrato areia e terra orgânica, apresentaram valores superiores de porcentagem de germinação em quase todos os tratamentos quando comparado aos tratamentos que utilizaram apenas a areia como substrato, dados estes que constatam com Resende et al. (2011) onde afirmam que, apesar da variação ocorrida nas diferentes variáveis, os resultados indicaram que a presença da matéria orgânica no substrato pode ter favorecido maior capacidade de retenção de água consequentemente maior germinação.

O tempo médio de germinação (TMG) de Tectona grandis L.f. obteve valores que não diferiram estatisticamente em quase todos os tratamentos, ou seja, apresentou-se o menor tempo médio para o tratamento $\mathrm{T} 2$, seguidos pelo tratamento $\mathrm{T} 7$ e $\mathrm{T} 8$. O tratamento que obteve o maior tempo médio de germinação foi tratamento T1 (testemunha com substrato composto por areia), demonstrando ser o tratamento menos eficiente para esta variável.

As sementes com os maiores índices de velocidade de germinação (Tabela 2) começaram emergir a partir da segunda semana após a semeadura das sementes. Segundo Vieira et al. (2009) os melhores desempenhos dos tratamentos é provavelmente resultado da maior eficiência dos procedimentos em proporcionar o aumento da permeabilidade do pericarpo sem danificar o embrião das sementes.

Tabela 2. Percentagem de germinação, índice de velocidade, velocidade e tempo médio de germinação de sementes de Tectona grandis L.f., utilizando métodos diferentes de superação de dormência.

\begin{tabular}{lcccc}
\hline \multicolumn{4}{c}{ Variáveis } \\
\hline Tratamentos & Germinação, $\%$ & $\begin{array}{c}\text { Índice de velocidade de } \\
\text { germinação }\end{array}$ & $\begin{array}{c}\text { Velocidade média de } \\
\text { germinação }\end{array}$ & $\begin{array}{c}\text { Tempo médio } \\
\text { de germinação }\end{array}$ \\
T1 & $13,00 \mathrm{c}$ & $0,15 \mathrm{~b}$ & $0,021 \mathrm{a}$ & $47,40 \mathrm{a}$ \\
T2 & $27,00 \mathrm{bc}$ & $0,47 \mathrm{~b}$ & $0,037 \mathrm{a}$ & $26,57 \mathrm{~b}$ \\
T3 & $9,00 \mathrm{c}$ & $0,15 \mathrm{~b}$ & $0,029 \mathrm{a}$ & $33,90 \mathrm{ab}$ \\
T4 & $24,00 \mathrm{c}$ & $0,46 \mathrm{~b}$ & $0,032 \mathrm{a}$ & $31,50 \mathrm{~b}$ \\
T5 & $26,00 \mathrm{bc}$ & $0,50 \mathrm{~b}$ & $0,033 \mathrm{a}$ & $30,13 \mathrm{~b}$ \\
T6 & $65,00 \mathrm{a}$ & $1,40 \mathrm{a}$ & $0,032 \mathrm{a}$ & $30,80 \mathrm{~b}$ \\
T7 & $45,00 \mathrm{~b}$ & $1,07 \mathrm{a}$ & $0,036 \mathrm{a}$ & $27,39 \mathrm{~b}$ \\
T8 & $16,00 \mathrm{c}$ & $0,29 \mathrm{~b}$ & $0,037 \mathrm{a}$ & $28,82 \mathrm{~b}$ \\
T9 & $26,00 \mathrm{bc}$ & $0,45 \mathrm{~b}$ & $0,030 \mathrm{a}$ & $33,20 \mathrm{~b}$ \\
T10 & $23,00 \mathrm{c}$ & $0,50 \mathrm{~b}$ & $0,034 \mathrm{a}$ & $29,00 \mathrm{~b}$ \\
CV $(\%)$ & 18,32 & 17,20 & 13,26 & 10,82 \\
CV $(\%)$ & 18,32 & 17,20 & 13,26 & 10,82 \\
\hline
\end{tabular}

*Médias seguidas pela mesma letra não diferem significativamente entre si, a $5 \%$ de probabilidade pelo teste $\mathrm{t}$.

A interpretação da taxa de germinação permite verificar a superioridade no desempenho dos tratamentos T6 e T7 desde o início da germinação, pois a taxa aumentou substancialmente de acordo com os dias e obtiveram uma taxa de germinação final de $65 \%$ e $45 \%$ respectivamente sendo superior aos demais tratamentos (Figura 1). 


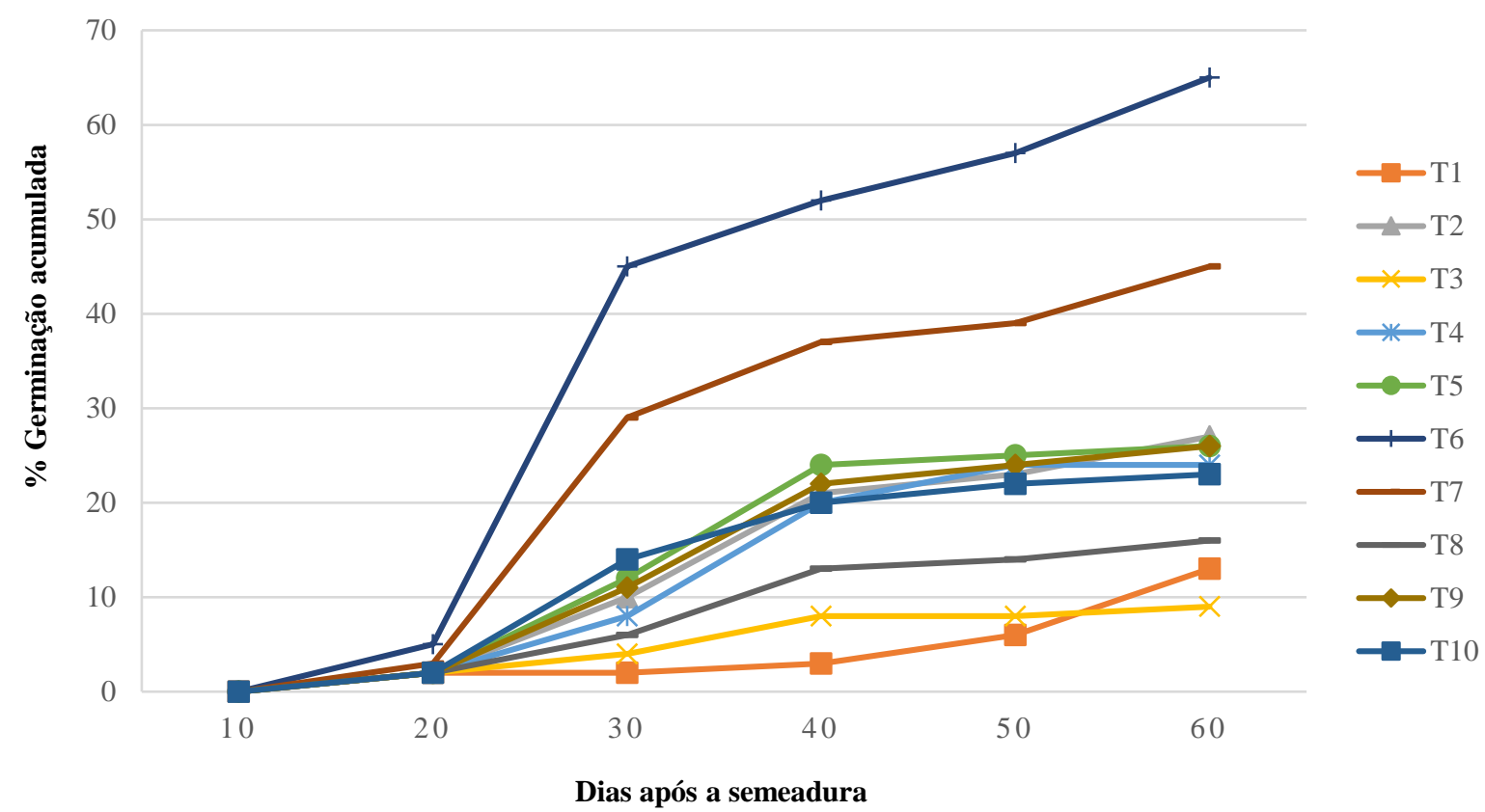

Figura 1. Taxa de germinação avaliada para as sementes de Tectona grandis L.f., submetidos a diferentes tratamentos de superação de dormência.

\section{Conclusão}

O tratamento (T6) testemunha com substrato composto de areia e terra orgânica foi o mais eficiente, visto que os resultados indicaram que a presença da matéria orgânica no substrato pode ter favorecido na maior capacidade de retenção de água e consequentemente maior germinação.

Contudo, vale ressaltar que o tratamento (T7) onde as sementes de Tectona grandis L.f. foram submetidas a uma temperatura média de $25{ }^{\circ} \mathrm{C}$ e acondicionadas sobre uma lona preta por 96 horas, apresentou alta taxa de germinação dentre os outros tratamentos de superação de dormência testados para essa espécie. Dessa forma, pode-se inferir que esse tratamento pode ser uma alternativa viável e sustentável para a superação de dormência de Tectona grandis L.f., pois tratamentos de superação de dormência que utilizam ácido sulfúrico demostram ser eficientes, entretanto podem ser custosos e perigosos aos usuários quanto à queimaduras e riscos no descarte da solução, pois se descartado de forma incorreta ocasiona sérios problemas ambientais.

\section{Referências}

Bezerra, L. A. S., Moraes, S. A. F., \& Oliveira, G. P. (2018). Superação de Dormência em Diásporos de Tectona grandis. Anais Da Academia Pernambucana de Ciência Agronômica, 15(2), 139-144.

Brasil. (2009). Regras para análise de sementes. Ministério Da Agricultura, Pecuária e Abastecimento. Secretaria de Defesa Agropecuária.

Dias, J. R. M., Caproni, A. L., Wadt, P. G. S., Silva, L. M., Tavella, L. B., \& Oliveira, J. P. (2009). Quebra de dormência em diásporos de teca (Tectona grandis L.f.). Acta Amazonica, 39(3), 549-554. https://doi.org/10.1590/S0044-59672009000300009

Favare, L. G. (2013). Adubação fosfatada e potássica em teca sob condições de campo [Universidade Estadual Paulista (UNESP)]. http://hdl.handle.net/11449/106666

Ferreira, R. Q. S., Camargo, M. O., Junior, M. R. S., Souza, P. B., \& Oliveira, L. M. (2016). Choque térmico na superação da dormência de diásporos de Tectona grandis L. f. Scientia Plena, 12(3).

Figueiredo, E. O., Oliveira, A. D., \& Scolforo, J. R. S. (2005). Análise econômica de povoamentos não desbastados de Tectona grandis Lf, na microrregião do baixo Rio Acre. Cerne, 11(4), 342-353.

Francisco, A. S. S., \& Carlos, A. V. A. (2016). The Assistat Software Version 7.7 and its use in the analysis of experimental data. African Journal of Agricultural Research, 11(39), 3733-3740. https://doi.org/10.5897/AJAR2016.11522 
IPEF. (2003). Identificação de espécies florestais: Tectona grandis(teca). Piracicaba, SP. In Instituto de Pesquisas e Estudos Florestais.

Labouriau, L. G. (1983). A germinação das sementes. OEA, Washington, 174 p.

Lamprecht, H. (1990). Silvicultura nos trópicos: ecossistemas florestais e respectivas espécies arbóreaspossibilidades e métodos de povoamento sustentado. Eschborn: Instituto de Silvicultura Da Universidade de Göttingen, 310-313.

Maguire, J. D. (1962). Speed of germination-Aid in selection and evaluation for seedling emergence and vigor. Crop Science, 2(2), 176-177.

Martins, C. C., Machado, C. G., \& Cavasini, R. (2008). Temperatura e substrato para o teste de germinação de sementes de pinhão-manso. Ciência e Agrotecnologia, 32(3), 863-868. https://doi.org/10.1590/S1413-70542008000300024

Menezes, W. M. (2017). Efeito da modificação térmica em escala industrial na qualidade da madeira de Tectona grandis Linn. F. Tese (doutorado) - Universidade Federal de Santa Maria, Programa de Pós-Graduação em Engenharia Florestal [142] Coleção de teses do Programa de Pós-Graduação em Engenharia Florestal.

Pasa, M. C., \& Nascimento, T. J. B. (2012). Germinação de Tectona grandis L. f. e a etnobotânica no distrito de Água da Prata. Brasnorte, Mato Grosso. FLOVET-Boletim Do Grupo de Pesquisa Da Flora, Vegetação e Etnobotânica, 1(1).

Raposo, A., Fermino Junior, P. C. P., Teixeira, R. B., \& Pereira, J. E. S. (2010). Produção de mudas de teca por micropropagação. Embrapa Acre-Circular Técnica (INFOTECA-E).

Resende, S. V., Crepaldi, I. C., Pelacani, C. R., \& Brito, A. L. (2011). Influência da luz e substrato na germinação e desenvolvimento inicial de duas espécies de Calliandra Benth: (Mimosoideae Leguminosae) endêmicas da Chapada Diamantina, Bahia. Revista Árvore, 35(1), 107-117. https://doi.org/10.1590/S0100-67622011000100013

Vieira, A. H., Rocha, R. B., \& Rebelo, A. M. (2009). Avaliação de métodos para a superação de dormência de diásporos de teca (Tectona grandis Lf). FLORESTA, 39(2). https://doi.org/10.5380/rf.v39i2.14555

\section{Histórico:}

Recebido: 20 de agosto de 2020 . Aprovado: 21 de setembro de 2020. Disponível online: 12 de dezembro de 2020
Licenciamento: Este artigoé publicado na modalidade Acesso Aberto sob a licença Creative Commons Atribuição 4.0 (CC-BY 4.0), a qual permite uso irrestrito, distribuição, reprodução em qualquer meio, desde que o autor e a fonte sejam devidamente creditados. 